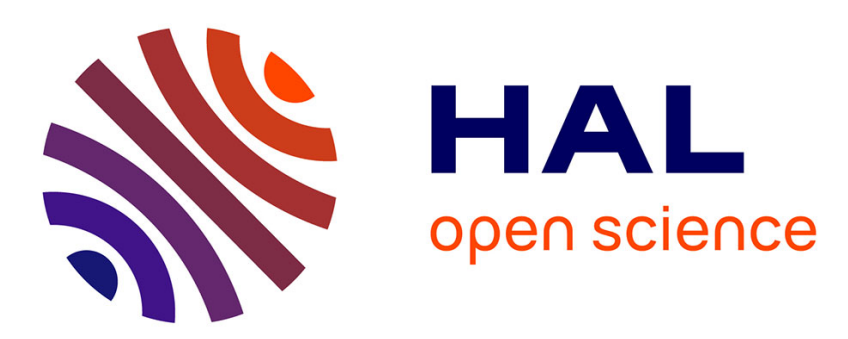

\title{
Effect of particles' characteristics and road surface's texture on the tire/road friction
}

\author{
Yosra Hichri, Veronique Cerezo, Minh Tan Do, Hassan Zahouani
}

\section{To cite this version:}

Yosra Hichri, Veronique Cerezo, Minh Tan Do, Hassan Zahouani. Effect of particles' characteristics and road surface's texture on the tire/road friction. Surface Topography: Metrology and Properties, 2018, 3 (6), 10.1088/2051-672X/aad063 . hal-01852237

\section{HAL Id: hal-01852237 \\ https://hal.science/hal-01852237}

Submitted on 1 Aug 2018

HAL is a multi-disciplinary open access archive for the deposit and dissemination of scientific research documents, whether they are published or not. The documents may come from teaching and research institutions in France or abroad, or from public or private research centers.
L'archive ouverte pluridisciplinaire HAL, est destinée au dépôt et à la diffusion de documents scientifiques de niveau recherche, publiés ou non, émanant des établissements d'enseignement et de recherche français ou étrangers, des laboratoires publics ou privés. 


\title{
Effect of particles' characteristics and road surface's texture on the tire/road friction
}

\author{
Y Hichri ${ }^{1}$, V Cerezo ${ }^{1}$, M T Do $^{1}$ and H Zahouani ${ }^{2}$ \\ ${ }^{1}$ IFSTTAR, AME, EASE, F - 44344 Bouguenais, France \\ ${ }^{2}$ Laboratory of Tribology and Dynamic of Systems \\ University of Lyon, ENISE-ECL-ENTPE. UMRS CNRS 5513 \\ 36, Avenue Guy de Collongue, 69131 Ecully Cedex. France \\ E-mail: yosra.hichri@ifsttar.fr
}

\begin{abstract}
This paper presents a laboratory study to investigate the lubrication induced by particles deposited on road surfaces which is responsible for the increase of accidents at the first rain after a long dry period. Particles are extracted from sediments collected at a catchment area and characterized by their chemical composition and size distribution. Protocol to simulate the particle deposit on the road surface and their compaction by the traffic is described. The test program includes variables such as particle concentrations, particles' size fractions and surface textures. Dry friction tests are conducted using the Skid Resistance Tester which simulates the sliding friction between a rubber slider and the test surface. Friction is lowered when the surface is covered by particles, compared with a clean surface. Repeated passages of the slider induce an increase of friction coefficient until reaching a stable value. Particles' flows during a friction run are separated into those ejected from the sample, those stored by the surface macrotexture and those that stay on the test surface; this study demonstrated that the friction coefficient is closely related to the quantity of particles available on the test surface. SEM analysis shows on the other hand that these particles are mainly trapped by the surface microtexture. Similar behavior between fine particles and powder in terms of lubrication mechanisms is observed.
\end{abstract}

\section{Introduction}

Previous studies showed that the occurrence of road accidents is statistically high at the first rain after a long dry period. Eisenberg (2004) found a significantly increasing crash risk with the number of dry days since the last rain. This excess risk is generally attributed to the accumulation of fine particles on the road surface. This contamination is due to both non-exhaust emission of traffic (tires, brakes, etc.) and vegetation debris. Egodawatta (2007) observed that particle's build-up is a function of the number of dry days and other weather conditions such as wind characteristics, traffic, etc. Shakely et al. (1980) found on the other hand that the tire/road friction decreases with increasing dust concentration.

Despite the above observations, the link between particles deposited on road surfaces and the tire/road friction is not well established, mainly due to a lack of understanding of involved mechanisms. At a microscopic scale it has been highlighted, in the case of metallic wheel/rail contact (Descartes et al 2008), that contaminants affect surface properties, adhesion or electrical insulation, and possibly damage or protect the contacting surfaces; thus they have a significant effect on the contact behavior. Heshmat (1993) has demonstrated that solid particles can form load-carrying lubricant films which exhibit a behavior resembling that of fluid films. Mills et al (2009) studied friction on dry floors covered by particulate contaminants and stated that there is a critical size of the particles (around 50-60 $\mu \mathrm{m}$ ) above which lubrication between a shoe's sole and the floor is due to particles rolling one on the other and below which shearing of the particles' layer (formed from particles' cohesive forces) is predominant. The floor surface roughness can trap particles and contributes to the shearing of the particle layer (Mills et al 2009).

In a previous study (Hichri et al 2017a), a test protocol to assess dry friction on road surfaces contaminated 
by particles was developed. These authors showed that particles lubricate the tire/road interface and confirmed the particles trapping - as a lubrication mechanism - stated by Mills et al (2009). In this paper, efforts have been continued to assess the effect of influential factors such as the road surface texture and the particles' size and concentration. From friction tests performed on surfaces with different textures and covered by particles of different concentrations and sizes, the particles' flows at the tire/road interface are deduced using the third body concept.

\section{Experiments}

\subsection{Test samples}

Two aluminum rectangular slabs (surface of $130 \mathrm{~mm} \times 80 \mathrm{~mm} \approx 0.01 \mathrm{~m}^{2}$ ) are used. A surface roughness similar to that of a road surface is obtained by sandblasting the surface with corundum particles (diameter superior to $2 \mathrm{~mm}$ ) to create the microtexture (surface irregularities whose dimensions are below $0.5 \mathrm{~mm}$ horizontally and vertically) and grooving to create macrotexture (surface irregularities whose dimensions range between $0.1 \mathrm{~mm}$ and $20 \mathrm{~mm}$ vertically, and between $0.5 \mathrm{~mm}$ and $50 \mathrm{~mm}$ horizontally). One slab is sandblasted (Fig. 1a), named "Sandblasted" in the paper, and the other is sandblasted and grooved (Fig. 1b), named "Chocolate". $S_{\mathrm{q}}$ for Sandblasted and Chocolate is respectively $13.6 \mu \mathrm{m}$ and $13.9 \mu \mathrm{m}$ (mean of $\mathrm{S}_{\mathrm{q}}$ values calculated from three areas of $5 \mathrm{~mm} \times 5 \mathrm{~mm})$. Grooves have a triangular shape $(2 \mathrm{~mm}$ in width at its basis and $1 \mathrm{~mm}$ in depth). It creates a grid with regular squares of $10 \mathrm{~mm}$ aside.

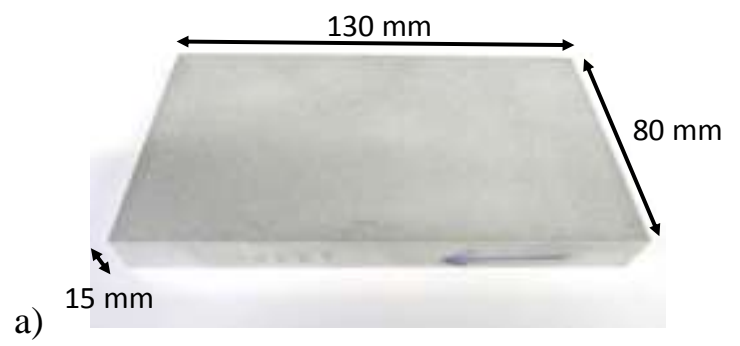

a)

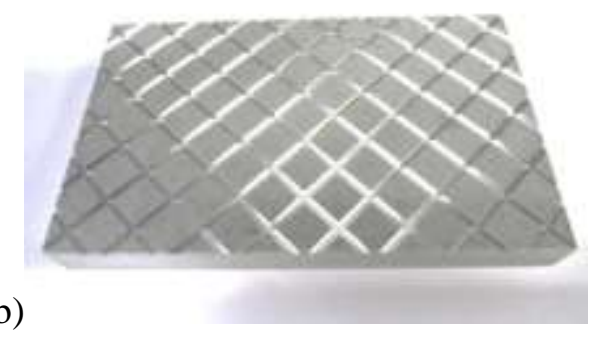

Figure 1. "Sandblasted" (a) and "Chocolate" (b) slabs.

\subsection{Particles collection and characterization}

Particles are collected at the catchment area of Chevire bridge with 90,000 vehicles daily $(8.5 \%$ of trucks) (Figure 2). Runoff water from the South part of the bridge is discharged to this area. Collecting particles using a vacuum machine, as practiced in previous studies (Vaze and Chiew 2002, Wilson 2006), would be an appropriate option but it would provide too small quantity of particles for laboratory tests. 


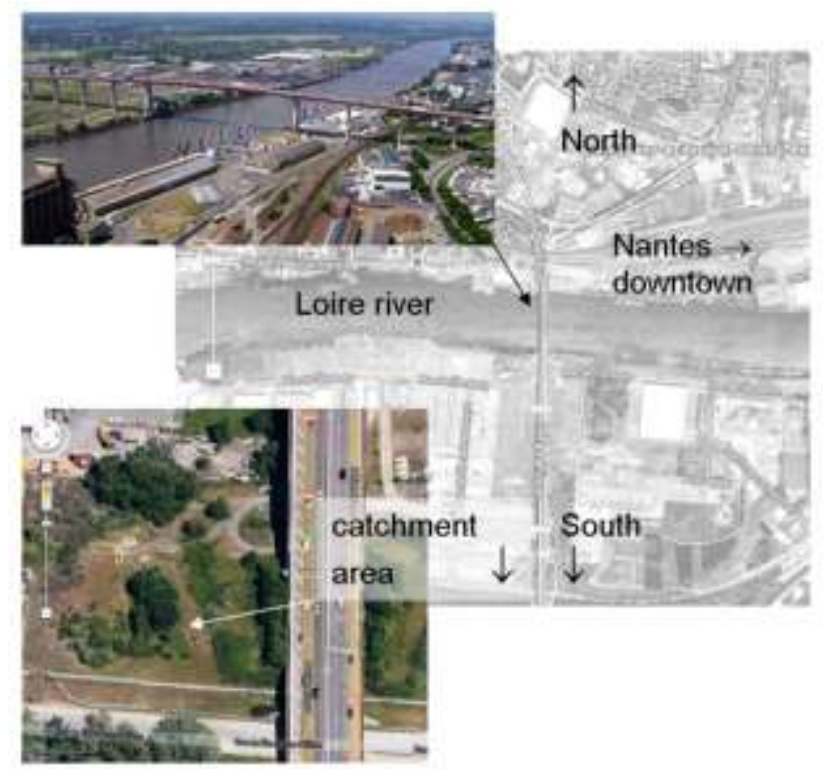

Figure 2. Particles' collection site (Hichri et al., 2017b)

The sediments extracted from the catchment area are dried at $40^{\circ} \mathrm{C}$ during four days and sieved to keep only particles smaller than $100 \mu \mathrm{m}$ that affect surface properties and friction (Descartes et al 2008, Arias-Cuevas et al 2010). SEM (Scanning Electron Microscopy) observations of particles show that they exhibit various shapes and sizes. Moreover, particles mainly contain silica and metallic elements that can be due to the wear of braking system and tires (Fig. 3). Na, K and Mg elements could come from industrial sites located in the neighborhood of the bridge.

Dried particles are sieved to obtain four size fractions: $0-40 \mu \mathrm{m}, 40-50 \mu \mathrm{m}, 50-80 \mu \mathrm{m}, 80-100 \mu \mathrm{m}$. Values are chosen with respect to the critical size (around 40 to $50 \mu \mathrm{m})$ separating "fine" $(0-40 \mu \mathrm{m}$ and $40-50 \mu \mathrm{m})$ and "coarse" (50-80 $\mu \mathrm{m}$ and $80-100 \mu \mathrm{m})$ particles' families (based on Mills et al (2009) analyses).

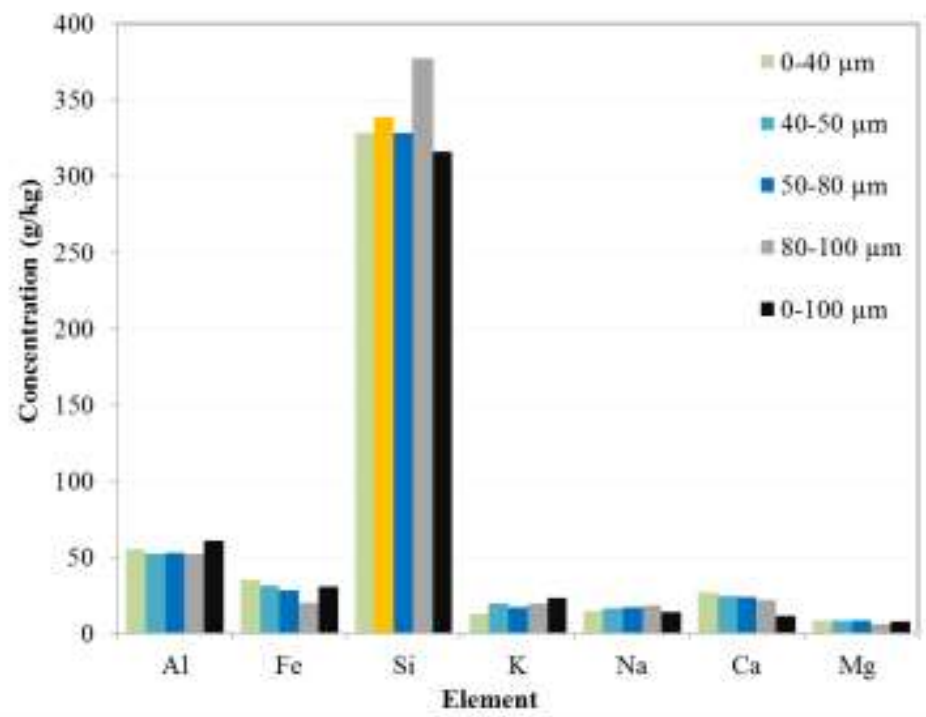

Figure 3. Chemical composition for different size fractions of particles

\subsection{Particles arrangement on the surface}

For each particle size fraction, three quantities of $0.1 \mathrm{~g}, 0.2 \mathrm{~g}$ and $0.4 \mathrm{~g}$ of dry particles are laid on the test surfaces, which represent respectively $10 \mathrm{~g} / \mathrm{m}^{2}, 20 \mathrm{~g} / \mathrm{m}^{2}$ and $40 \mathrm{~g} / \mathrm{m}^{2}$ in concentrations. The $20 \mathrm{~g} / \mathrm{m}^{2}$ concentration is representative of the amount of particles in urban areas (Vaze and Chiew 2002, Deletic and Orr 2005) and the two other represent limit values. 
a)

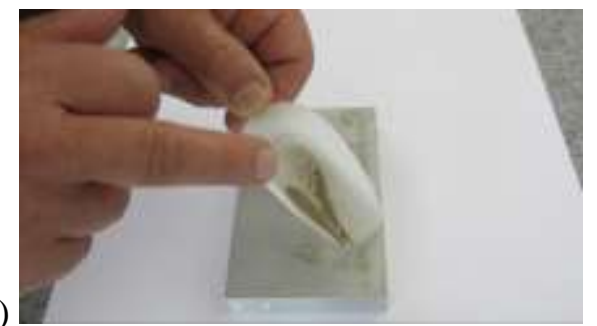

b)

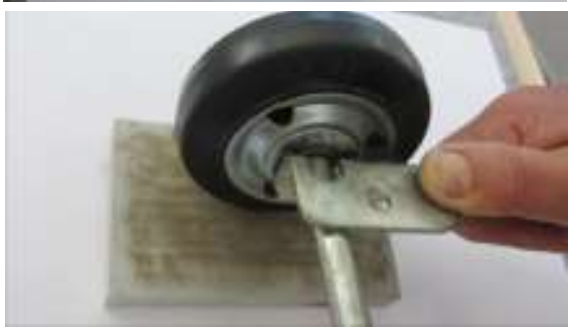

c)

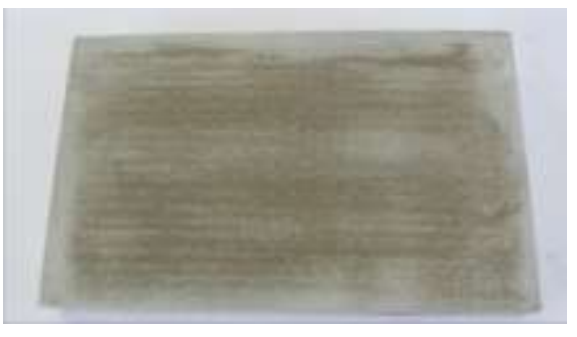

Figure 4. Particles' arrangement protocol (a: spreading; b: compaction; c: surface with particles) from (Hichri et al., 2017b).

Particles are spread manually on the slabs (Fig. 4a) and then compacted (simulation of vehicular traffic) by means of a wheel mounted on a metallic arm (Fig. 4b). Compaction is performed through 60 repeated passes of the wheel. This protocol allows obtaining a homogenous distribution of the particles. Figure 4c shows a slab covered by particles.

\subsection{Friction tests}

Friction tests are performed by means of a Skid Resistance Tester Pendulum (Fig. 5), which is well-known in civil engineering field to assess skid resistance in laboratory and on real road. The Pendulum is composed of an articulated arm equipped at its end with a rubber pad, which slides on the test surface. When the arm is released from its initial horizontal position, it moves up to a height where values on a graduated scale can be read and correspond to a friction coefficient. The test is standardized (CEN 2009).

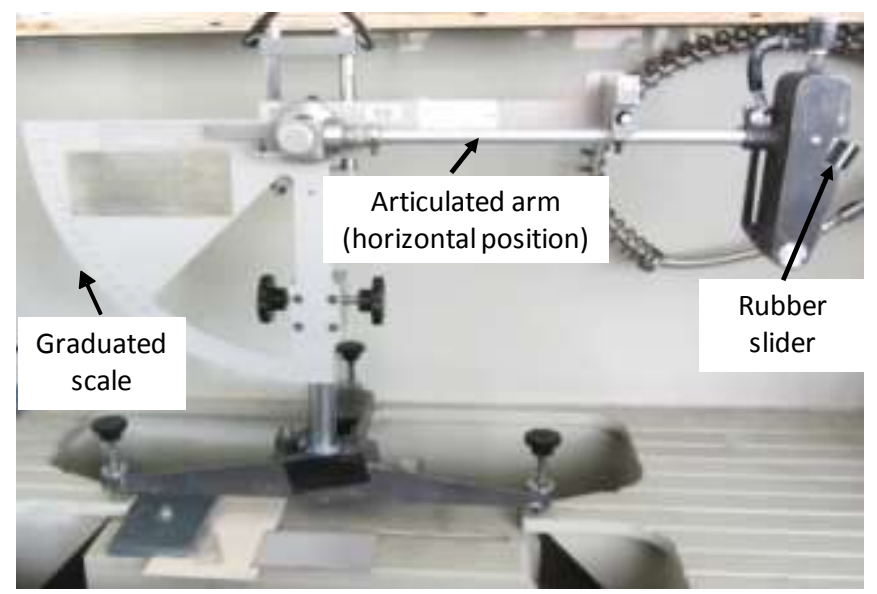

Figure 5. Skid Resistance Tester Pendulum

\subsection{Test protocol}


The test protocol follows the following steps:

- On dry and clean surfaces (step numbered 0): measurement of 3D height cartographies and friction coefficient; weighing of the sample (mass $\mathrm{m}_{0}$ ).

- Particles arrangement (see 2.3).

- On surfaces covered by particles (step numbered $\mathrm{i}, \mathrm{i} \geq 1$ ): friction measurement; weighing of the sample before/after friction measurement.

- When the friction coefficients recorded at three successive steps do not differ more than \pm 0.01 , stop the series.

At each step, only one run is performed for friction measurement. This is due to the fact that the distribution of particles evolves at each friction run. Nevertheless, to assess the repeatability of the test method, some test series were repeated and it was found that values of the friction coefficient at every step are very repeatable (coefficient of variation - ratio standard deviation/mean - less than $4 \%$ at each step) (Hichri et al 2017a).

A new rubber pad is mounted on the Skid Resistance Tester for each test series. The rubber is carefully wiped after each friction measurement to limit the contamination of the pad. A high resolution optical sensor, called Infinite Focus, based on the focus variation principle is used to capture 3D images from which surface texture profiles or cartographies are extracted. 3D cartographies are measured on areas of $5 \mathrm{~mm} \times 5 \mathrm{~mm}$ in dimensions, located at the center and at the two extreme ends of the specimen (where the friction slider respectively touches and leaves the test surface). A lens enabling 20 times magnification is used for the capture. The vertical resolution of the sensor is $50 \mathrm{~nm}$. Analyses are performed using the Mountains Map ${ }^{\circledR}$ software. Non-measured points are first replaced by values of neighbor points. A lowpass filter is then used to remove the form of the surface. Finally, the cartography is levelled using a leastsquare plane. Texture parameters are then calculated on the extracted profiles. SEM observations are made in the same areas.

\subsection{Calculation of the mass of particles}

The mass loss of the rubber pad during a series of friction measurements is negligible (few milligrams) compared with the initial mass of particles (hundreds of milligrams). Moreover, the clean sample exhibits the same weight at the beginning and end of each test series. Thus, the amount of detached particles from the two contacting bodies (slider and sample) is negligible. It is assumed in the rest of the paper that the mass of the particles matches the difference in weight between contaminated and clean states.

The mass of particles at step (i) can be then calculated as follows:

$$
\mathrm{m}_{\text {particles,i }}=\mathrm{m}_{\text {specimen,i }}-\mathrm{m}_{\text {specimen }, 0}
$$

where $m_{\text {particles, } i}$ is the mass of particles at step (i); $m_{\text {specimen, } i}$ is the mass of the specimen at step (i); $\mathrm{m}_{\text {specimen, } 0}$ is the mass of the clean specimen.

\section{Results}

\subsection{Variations of friction and mass of particles}

Variations of friction coefficient on "Sandblasted" and "Chocolate" surfaces are provided in figure 6. It can be observed that the friction coefficient on contaminated surfaces (steps $i ; i \geq 1$ ) is always lower than that of a clean surface (step 0 ). The friction coefficient increases with the number of friction runs and reaches a stable value. 


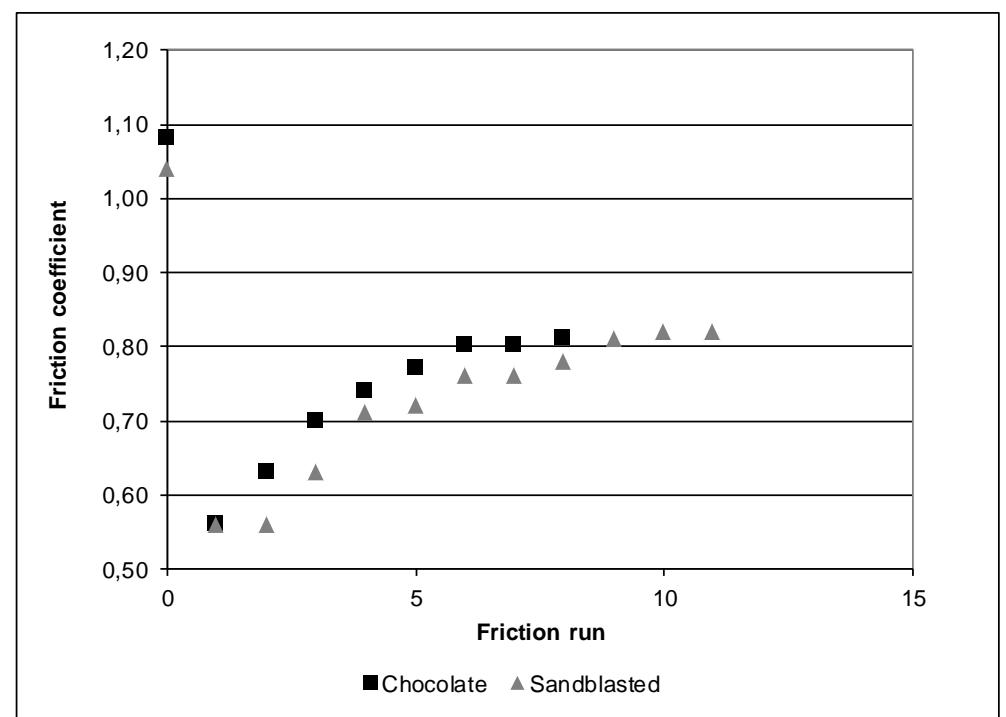

Figure 6. Friction coefficient evolution on "Chocolate" and "Sandblasted" contaminated surfaces

The final value of friction coefficient is close for the two surfaces ( 0.82 and 0.80 in average for respectively Sandblasted and Chocolate). However, the evolution is more rapid for Chocolate than for Sandblasted.

Figure 7 shows that the mass of particles decreases when the friction coefficient increases. According to Mills et al (2009), a shear effect due to the slider induces a reduction of the particles layer thickness until the surface asperities emerge and restore direct contact between the slider and the surface. A decrease of particles' mass increases then the slider/surface contact area and explains the friction increase.

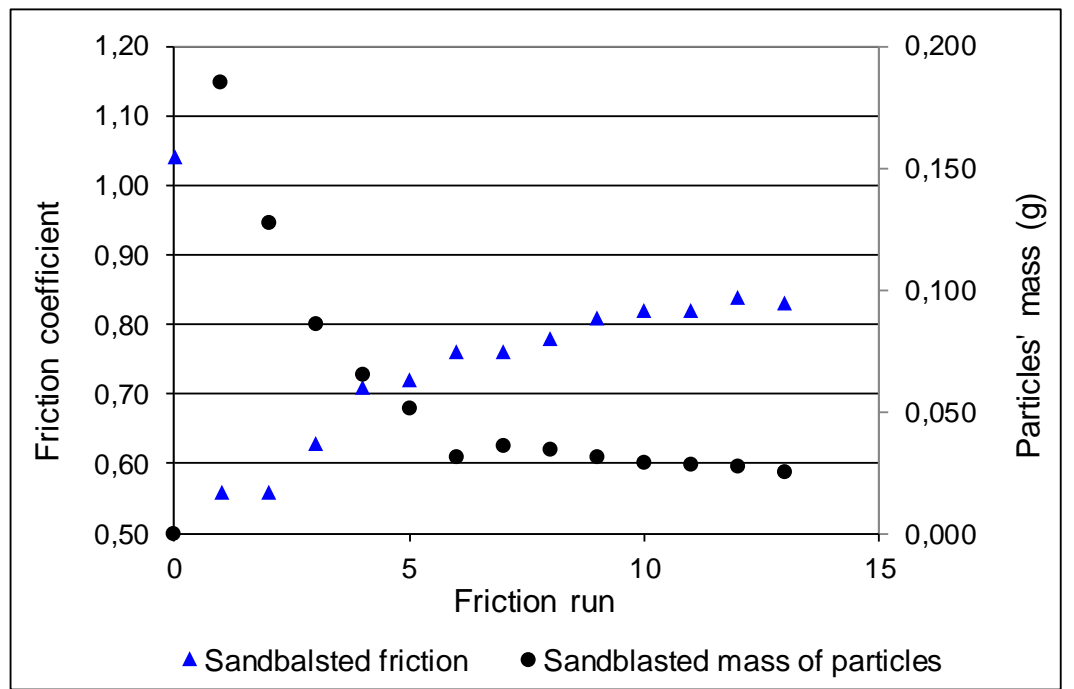

Figure 7. Friction coefficient and particles mass evolution during a friction test (Sandblasted surface; $20 \mathrm{~g} / \mathrm{m}^{2}$; fraction $0-40 \mu \mathrm{m})$

\subsection{Effect of surface texture}

\subsubsection{Particles trapping by the surface microtexture}

SEM observations show that the surface coverage by particles decreases after successive passages of the friction slider. In addition, the particles that remain on the surface are those trapped by the surface valleys; it would be difficult to remove these particles, which then continue to lubricate the interface and induce lower friction compared with a clean surface. 
a)

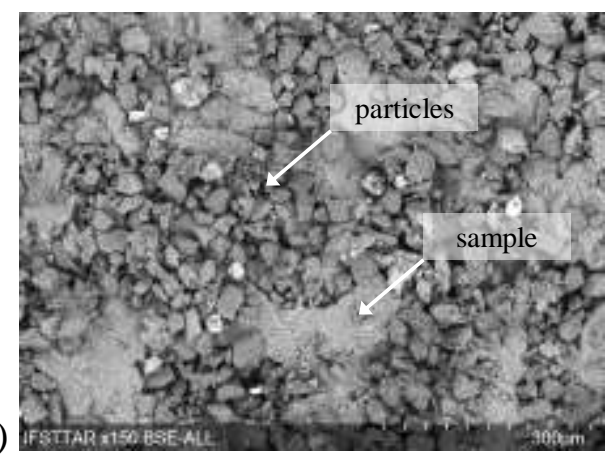

b)

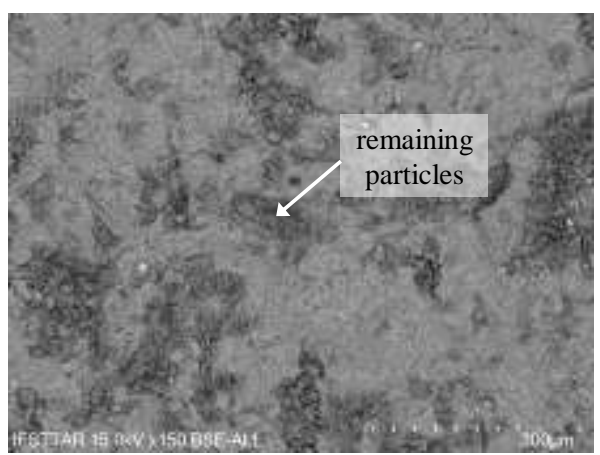

Figure 8 . SEM captions of a) the surface recovered by particles and b) the surface after 5 friction runs

\subsubsection{Particles storage by the surface macrotexture}

In figure 9, a sharp increase of friction on the Sandblasted surface can be observed for small quantity of particles (mass of particles around 0.03g). According to Heshmat (1993) who studied the powder lubrication, the sharp increase of friction can be due to the depletion of particles until the point where direct contact is established between the two first bodies (considering powder as a third body).

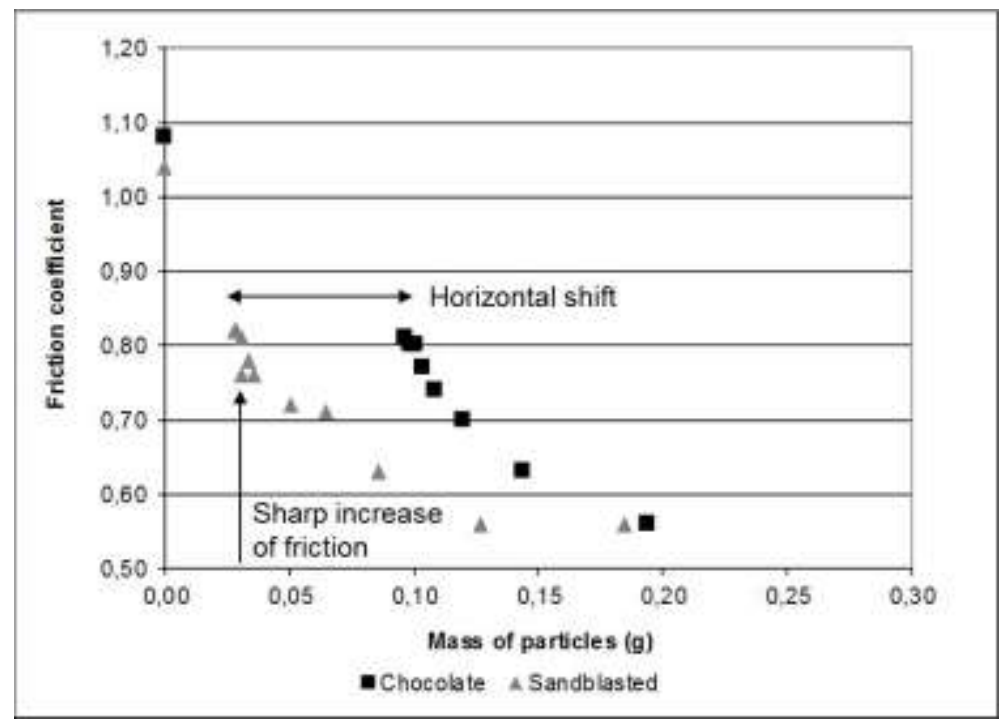

Figure 9. Friction coefficient evolution as a function of mass of particles $\left(20 \mathrm{~g} / \mathrm{m}^{2}\right.$; fraction $\left.0-40 \mu \mathrm{m}\right)$

A horizontal shift can also be seen between the two studied slabs, which means that different amount of particles generate the same friction coefficient! The explanation can be found in the presence of the grooves on the Chocolate slab, which store part of the weighed particles and, yet, do not contribute to the contact. Therefore, to be comparable, weighing results of Chocolate must be corrected to remove the mass of particles stored in the grooves. 
3.3. Mass analysis

Fillot et al (2007) demonstrated that the analysis of the wear-induced particles' mass can help to understand particles' flows inside the contact. Given the similarities between Fillot and coauthors' study and this study (movement of dry particles trapped between two rubbing surfaces), it is proposed to adopt the same approach to better interpret friction variations.

\subsubsection{Modeling and analysis of particles' flows}

Two particles' flows can be defined in the contact area (Fig. 10):

1) Ejection flow, which is composed of particles ejected from the contact area and those falling into the grooves;

2) Circulation flow, which is composed of particles retained by the surface valleys.

For friction analysis, only the circulation flow is of interest. However, weighing includes this flow and particles stored in the grooves. Therefore, a model is developed to isolate the circulation flow in the weighing.

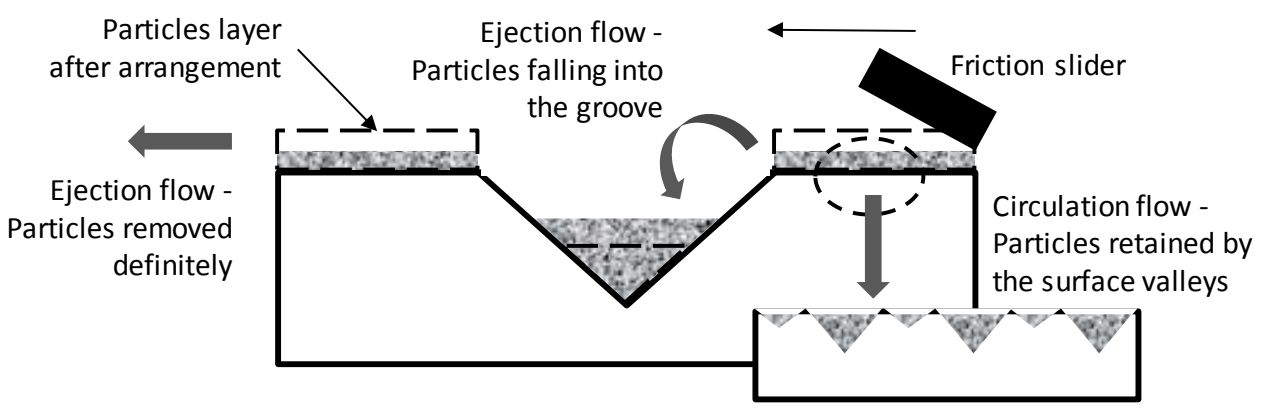

Figure 10. Particles' flows in the rubber pad/surface contact area (from Hichri et al., 2017c)

In figure 11 right, particles layer on Chocolate slab at run (i-1) is illustrated (mass $\left.m_{i-1}\right)$. At run i (Fig. 11 left), the extra quantity of particles falling into the grooves is supposed to represent a fraction $\mathrm{k}(0<\mathrm{k}<1)$ of $\mathrm{m}_{\mathrm{i}-1.1}$. It is assumed furthermore that $\mathrm{k}$ remains constant during a test series (for a given particles' concentration and size fraction).
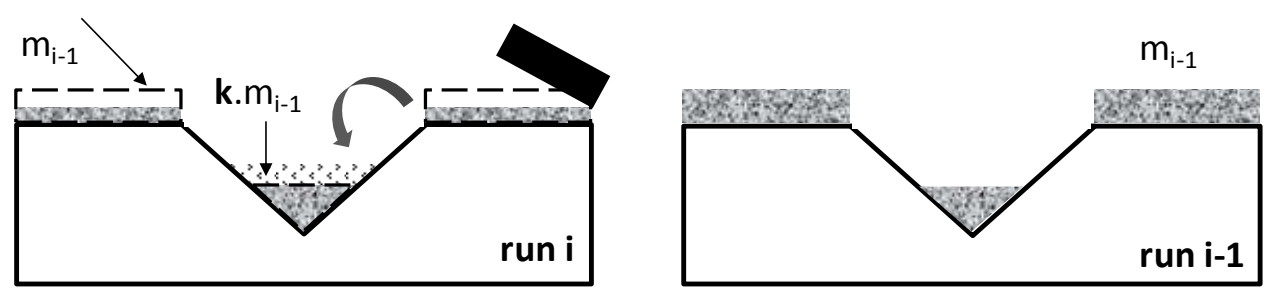

Figure 11. Quantity of particles falling into the grooves (from Hichri et al., 2017c)

For run $\mathrm{i}(\mathrm{i} \geq 2)$, one gets:

$$
\begin{gathered}
\mathrm{m}_{\text {particles }, \mathrm{i}}=\mathrm{m}_{\text {particles }, \mathrm{i}}^{\text {surface }}+\mathrm{m}_{\text {particles }, \mathrm{i}}^{\text {groove }} \\
\mathrm{m}_{\text {particles }, \mathrm{i}}^{\text {groove }}=\mathrm{m}_{\text {particles,i-1 }}^{\text {groove }}+\mathrm{km}_{\text {particles }, \mathrm{i}-1}^{\text {surface }}
\end{gathered}
$$

Where $\mathrm{m}_{\text {particles, } \mathrm{i}}$ is the weighed mass of particles at run (i); $\mathrm{m}_{\text {particles, } \mathrm{i}}^{\text {surface }}$ is the mass of particles on the surface at run (i); $\mathrm{m}_{\text {particles, } \mathrm{i}}^{\text {groov }}$ is the mass of particles in the grooves at run (i); and $\mathrm{k}$ is the fraction of extra particles falling into the grooves. 
For run 1, the amount of particles in the grooves is supposed to be:

$$
\mathrm{m}_{\text {particles,1 }}^{\text {groove }}=\mathrm{k} \mathrm{m}_{\text {particles, } 1}
$$

It is therefore possible to estimate the quantity of particles in the grooves $m_{\text {particles, } 1}^{\text {groove }}$ at run 1 (Eq. 4 ) and at the surface $m_{\text {particles }, 1}^{\text {surface }}\left(m_{\text {particles }, 1}^{\text {surface }}=m_{\text {particles }}^{\text {total }}-m_{\text {particles }, 1}^{\text {groove }}\right)$. These quantities are then used to estimate the quantity of particles in the grooves at run 2 ( $\left.\mathrm{m}_{\text {particles, } 1}^{\text {groove }}\right)$ (Eq. 3), from which the quantity of particles at the surface at run $2\left(\mathrm{~m}_{\text {particles, } 1}^{\text {surface }}\right)$ can be deduced (Eq. 2$)$. The calculations at run 2 can be repeated for the following runs.

\subsubsection{Estimation of mass of particles stored by the surface macrotexture}

As the microtexture of Sandblasted and Chocolate slabs is similar $\left(S_{\mathrm{q}}\right.$ are respectively $13.6 \mu \mathrm{m}$ and $13.9 \mu \mathrm{m}-$ see 2.1), it is assumed that the same mass of particles from the circulation flow provides the same friction coefficient. A criterion to determine $\mathrm{k}$ is then the superposition of the two sets of points in figure 8 .

Results are illustrated in figure 12. Figure 12a shows results for uncorrected and corrected masses of particles for the Chocolate. Figure 12b compares data from the slab with corrected mass for the Chocolate. Adjusted values of $\mathrm{k}$ are presented in table 1 .

a)
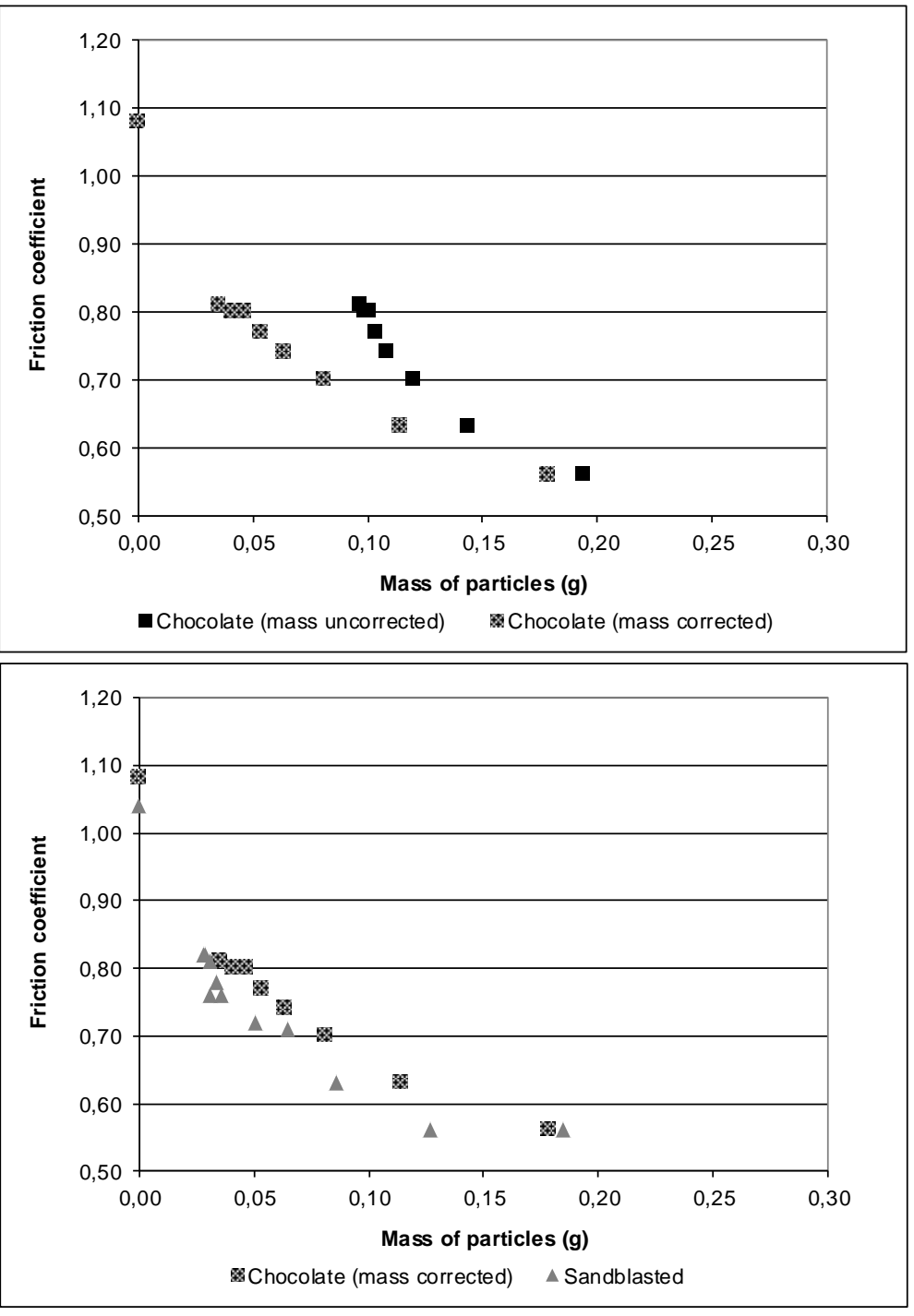
Figure 12. Friction coefficient evolution as a function of corrected and uncorrected masses of particles $\left(20 \mathrm{~g} / \mathrm{m}^{2}\right.$; fraction $\left.0-40 \mu \mathrm{m}\right)$

Table 1. Adjusted $\mathrm{k}$ factor for different particles' concentrations and fractions.

\begin{tabular}{lccc}
\hline Fraction & \multicolumn{3}{c}{ Concentration } \\
\cline { 2 - 4 } $0-40 \mu \mathrm{m}$ & $10 \mathrm{~g} / \mathrm{m}^{2}$ & $20 \mathrm{~g} / \mathrm{m}^{2}$ & $40 \mathrm{~g} / \mathrm{m}^{2}$ \\
\cline { 2 - 4 } $40-50 \mu \mathrm{m}$ & 0.10 & 0.09 & 0.09 \\
$50-80 \mu \mathrm{m}$ & 0.10 & 0.08 & 0.18 \\
$80-100 \mu \mathrm{m}$ & 0.18 & 0.25 & 0.20 \\
& 0.35 & 0.08 & 0.29
\end{tabular}

Values of $\mathrm{k}$ mean that between $8 \%$ and $35 \%$ of particles at the surface fall into the grooves at each friction run. Regarding the size of the grooves $\left(44 \mathrm{~mm}^{2}\right)$ and the tablet area $\left(100 \mathrm{~mm}^{2}\right)$, the ratio between them is 0.44 . It means that, in maximum, $44 \%$ of particles can fall into the grooves. This calculation should be refined but it shows that the adjusted values of $\mathrm{k}$ are in the order of what could be expected.

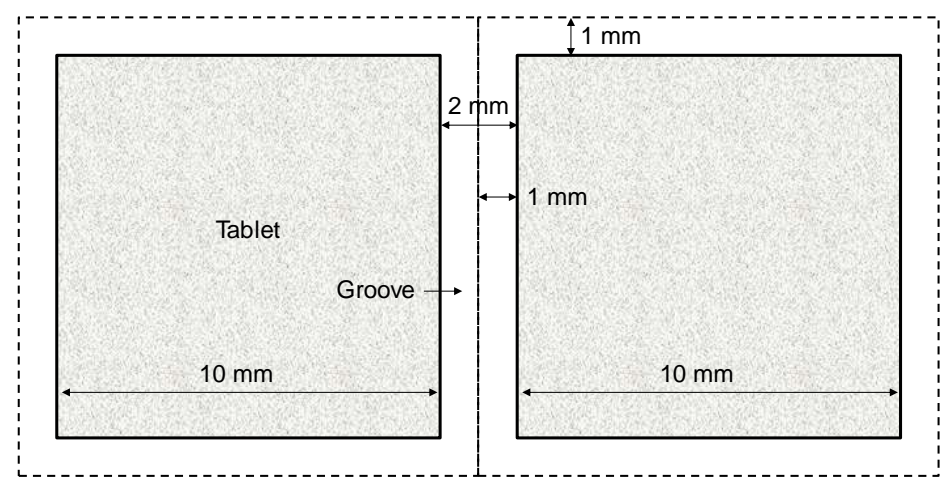

Figure 13. Dimensions of the tablets and the grooves

In figure 14, if one considers the $\mathrm{k}$ value of combination (concentration $20 \mathrm{~g} / \mathrm{m}^{2}$, fraction $80-100 \mu \mathrm{m}$ ) as unusual, it could be said that $\mathrm{k}$ increases for increasing particles' size, meaning that more coarse particles are expelled by the friction slider from the slider/surface contact area. This trend can be explained by analysis of

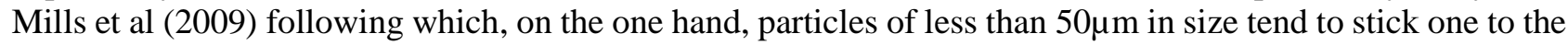
other due to cohesive forces and, as a consequence, form a layer and, on the other hand, particles bigger than $50 \mu \mathrm{m}$ tend to roll one on the other. The consequence of these two mechanisms is that it would be more difficult to expel fine particles $(<50 \mu \mathrm{m})$ than coarse ones $(>50 \mu \mathrm{m})$, explaining the resulted values of $\mathrm{k}$.

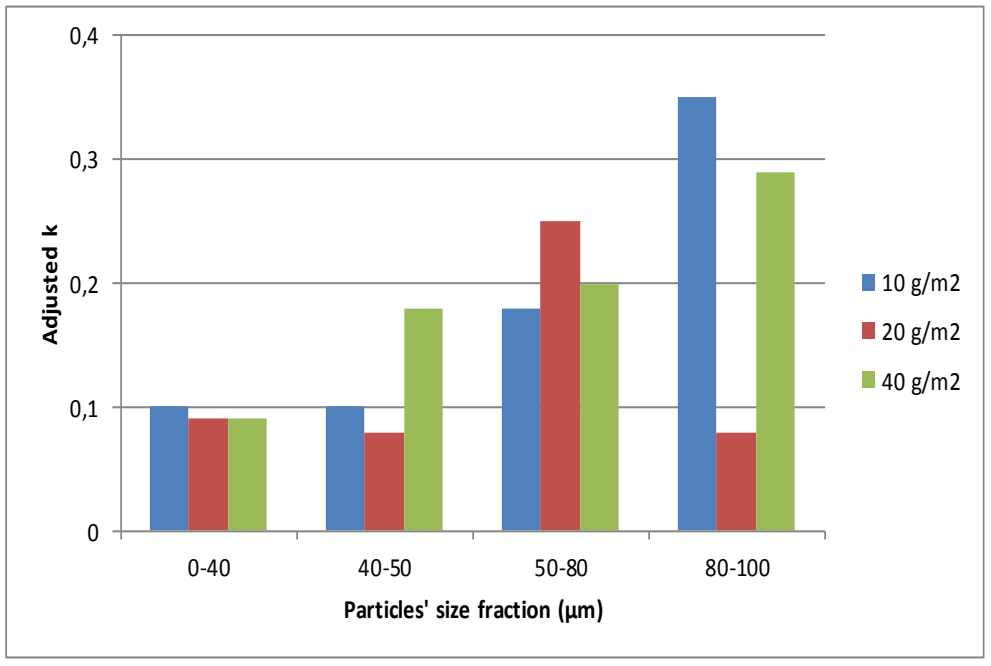


Figure 14. Variation of k factor for different particles' concentrations

\subsection{Relationship between friction and mass of particles}

\subsubsection{Effect of particles' size}

Figures 15a and 15c show variations of the friction coefficient with the number of friction runs at different particles' sizes for the two studied surfaces. For both surfaces, it can be seen that at a given step the friction coefficient increases with increasing particles' size. For fraction $80-100 \mu \mathrm{m}$, values of friction coefficient at stabilization are close to value at the beginning (clean state). For fraction $0-40 \mu \mathrm{m}$, values of friction coefficient at stabilization (around 0.8) are well below value at the beginning (around 1.05). These observations are a consequence of the particles' flows analyzed in the previous section. Actually, coarse particles are easily expelled by the rubber slider and the surface is cleaned more rapidly. Inversely, fine particles are trapped by the surface microtexture or form a layer and it is thought that the surface contamination will last longer.

a)
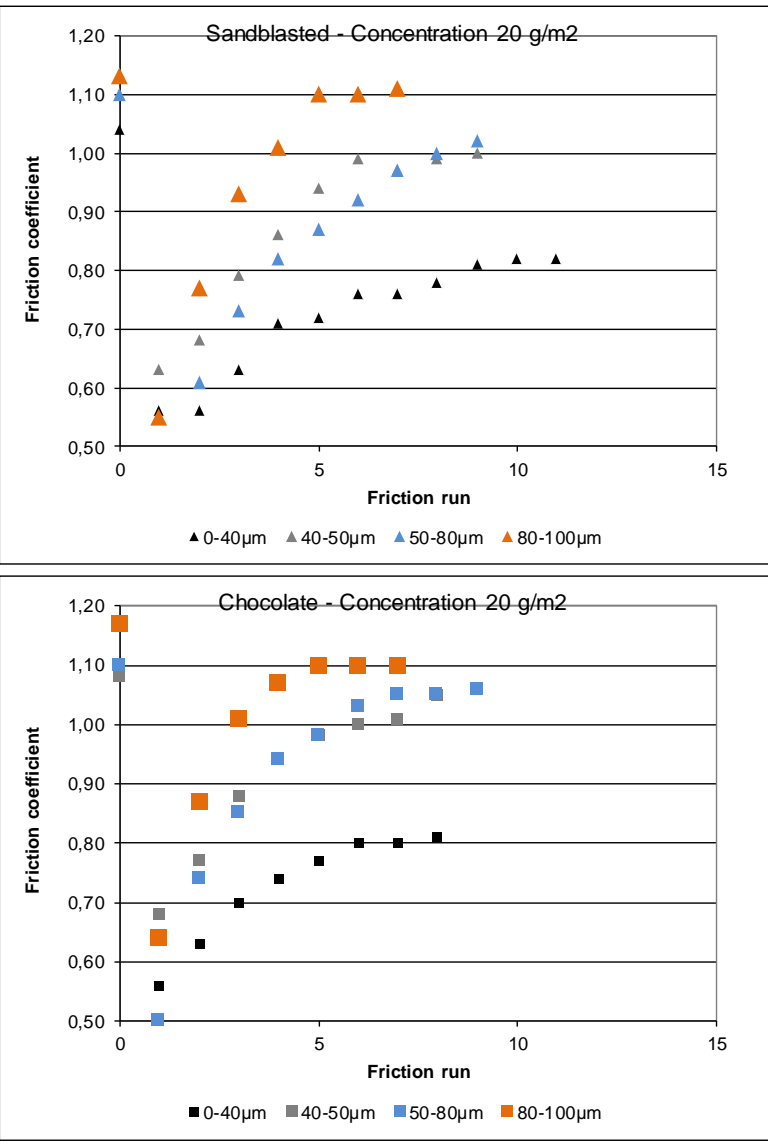

b)
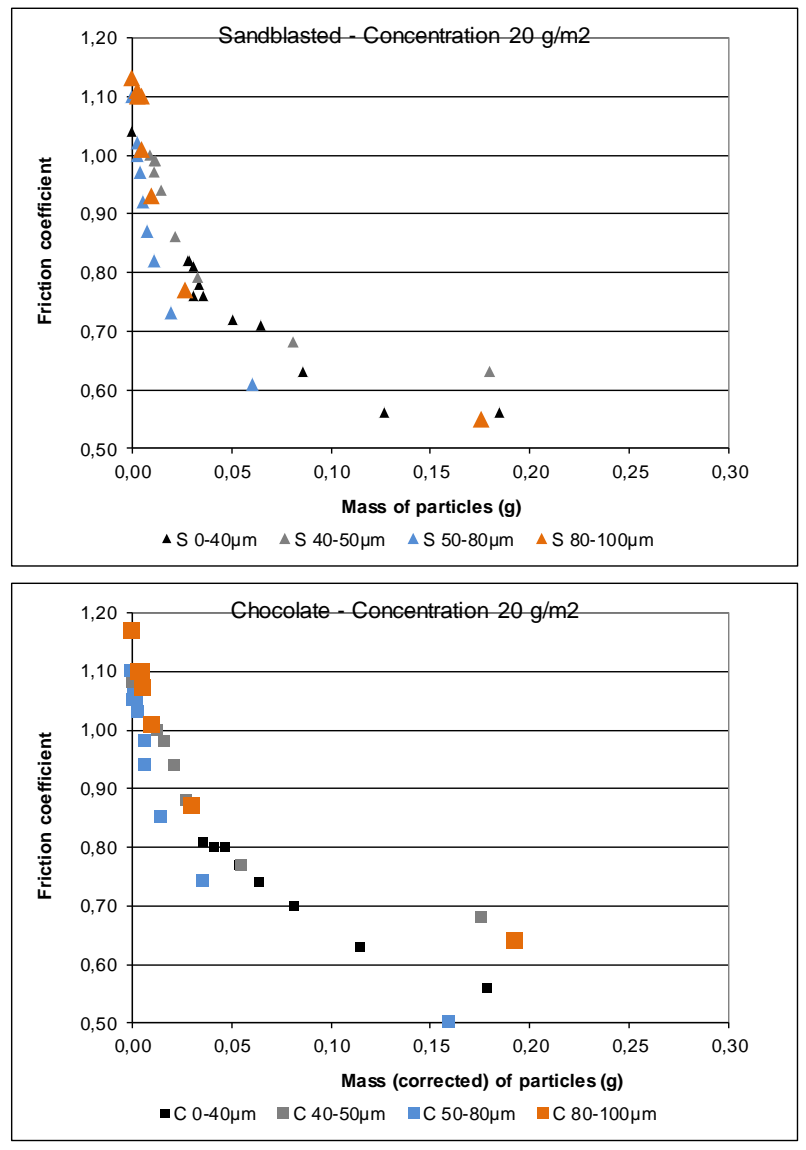

Figure 15. Variation of friction and mass of particles for different particles' sizes

In figures $15 \mathrm{~b}$ and $15 \mathrm{~d}$, friction coefficient is plotted against mass of particles (same friction data as in figures $14 \mathrm{a}$ and $14 \mathrm{c}$ respectively). It can be observed that the effect of particles' size is no more visible using this presentation. Based on analyses made by Mills et al (2009) on the size-dependent lubrication induced by particles (rolling for coarse particles and shearing for fine ones), one could expect some differences between the four fractions. Further understanding of particles' interactions would help to explain the obtaining of this master curve.

\subsubsection{Effect of particles' concentration}

In figures 16a and 16c, variations of the friction coefficient with the number of friction runs at different particles' concentrations for the two studied surfaces are shown. For fraction $0-40 \mu \mathrm{m}$, it can be seen that the friction recovering is longer for concentration $40 \mathrm{~g} / \mathrm{m}^{2}$ compared with the two other concentrations. For fraction $80-100 \mu \mathrm{m}$, this trend is confirmed but values of friction coefficient at stabilization are higher for concentration 
$20 \mathrm{~g} / \mathrm{m}^{2}$ compared with $10 \mathrm{~g} / \mathrm{m}^{2}$. No satisfactory argument is found to explain this difference.

a)
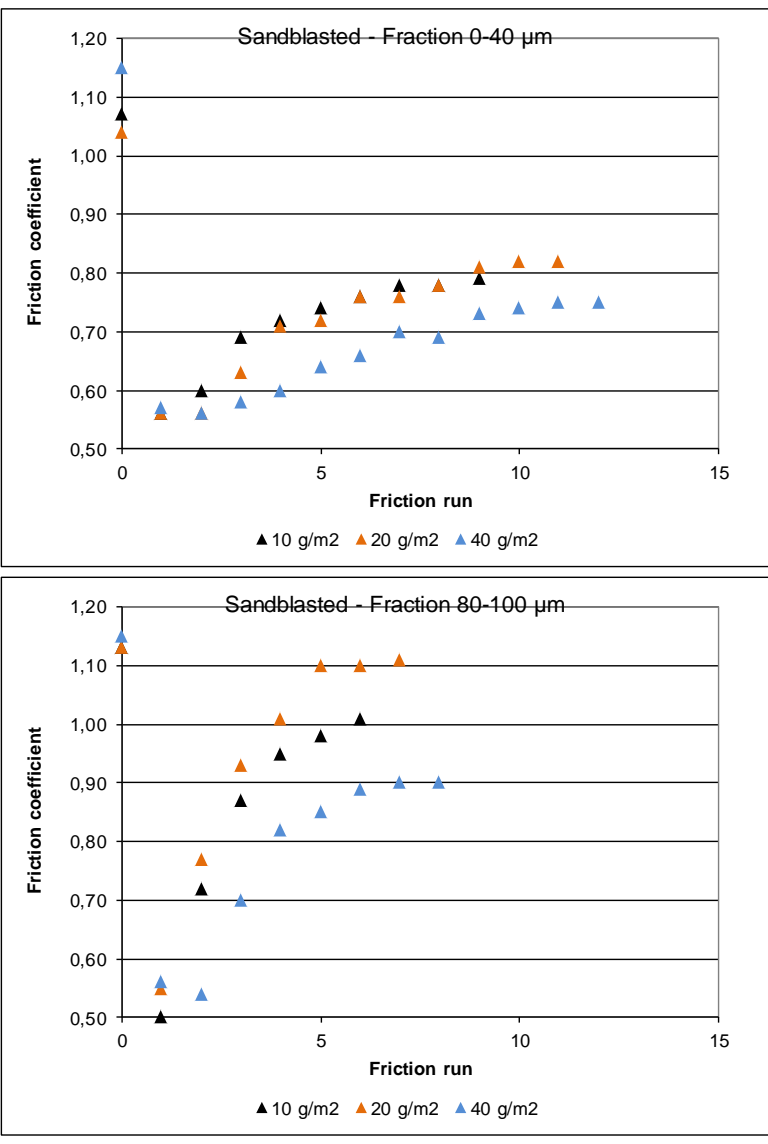

b)
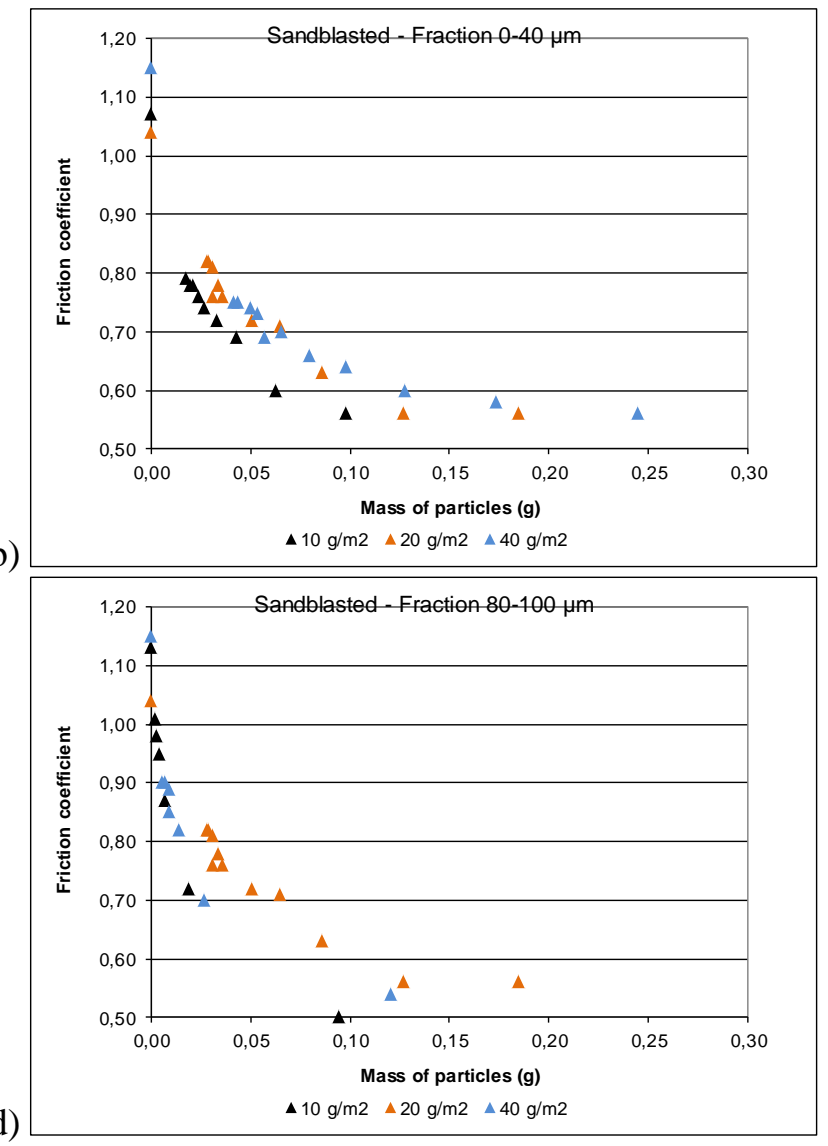

Figure 16. Variation of friction and mass of particles for different particles' concentrations

In figure $16 \mathrm{~b}$ and $16 \mathrm{~d}$, friction coefficient is plotted against mass of particles (same friction data as in figures $16 \mathrm{a}$ and $16 \mathrm{c}$ respectively). It can be observed that the effect of particles' concentration is no more visible using this presentation.

\section{Conclusions}

The lubrication of tire/road interface induced by particles deposited on the road surface was investigated in laboratory. Particles of different sizes (fractions of $0-40 \mu \mathrm{m}, 40-50 \mu \mathrm{m}, 50-80 \mu \mathrm{m}$ and $80-100 \mu \mathrm{m}$ ) were spread at different concentrations $\left(10 \mathrm{~g} / \mathrm{m}^{2}, 20 \mathrm{~g} / \mathrm{m}^{2}\right.$ and $\left.40 \mathrm{~g} / \mathrm{m}^{2}\right)$ on two surfaces having the same microtexture $\left(\mathrm{S}_{\mathrm{q}}\right.$ of $13.6 \mu \mathrm{m}$ and $13.9 \mu \mathrm{m}$ respectively) with and without macrotexture (simulated by grooves) respectively. The test protocol helps to evaluate the variation of friction coefficient, measured by a so-called Skid resistance tester Pendulum, as well as mass of particles with successive passes of the Pendulum's rubber slider simulating sliding of tire tread blocks on a road surface.

The effect of surface texture has been observed through two mechanisms: a trapping of particles by the roughness of surface microtexture and a storage of particles by the "reservoirs" created by surface macrotexture. The first mechanism induces continuing contamination of the road surface and a lower friction coefficient compared with a clean surface. The effect of the second mechanism is not clearly understood but it can be thought that stored particles can be entrained by the tire to the road surface and contaminate it (this mechanism can be studied in the future).

Particles smaller than $40 \mu \mathrm{m}$ can be trapped by surface microtexture or form a layer; by this fact, they are not easily expelled from the contact. Fractions higher than $40 \mu \mathrm{m}$ in size are less affected by the trapping mechanism and more easily expelled from the contact (ejected from the sample or stored by surface macrotexture). The consequence of this size effect is that friction recovering (the way friction coefficient of contaminated surfaces tends toward that of a clean surface) is slower when particles are smaller than $40 \mu \mathrm{m}$. 
The effect of particles' concentration is less visible even if a slower friction recovering was observed for the highest concentration $\left(40 \mathrm{~g} / \mathrm{m}^{2}\right)$.

Particles' flows inside the contact were modeled and a method was proposed to correct particles' weighing to analyze only the mass of particles present on the test surfaces. Within the frame of conducted experiments, it was observed that the friction coefficient decreases when the mass of particles increases. The striking point is that when friction coefficient is plotted against mass of particles, a master curve is obtained, regardless the particles' size and concentration.

\section{References}

Arias-Cuevas O, Li Z, Lewis R and Gallardo-Hernandez E A 2010 Rolling-sliding laboratory tests of friction modifiers in dry and wet wheel-rail contacts Wear 268 543-551.

Deletic A and Orr D W Pollution build-up on road surfaces Environmental Engineering 131(1) 49-59.

Descartes S, Desrayaud C and Berthier Y 2008 Experimental identification and characterization of the effects of contaminants in the wheel-rail contact Proc. IMechE Part F: J. Rail and Rapid Transit 222 207-216.

Egodawatta P (2007) Translation of small plot scale pollutant build-up and wash-off measurements to urban catchment scale PhD thesis Queensland University of Technology Australia.

Eisenberg D 2004 The mixed effects of precipitation on traffic crashes Accident Analys is and Prevention 36 637-647

EN 13036-4 2009 Method for measurement of slip/skid resistance of surface - Part 4: the Pendulum test.

Fillot N, Iordanoff I and Berthier Y 2007 Wear modeling and the third body concept Wear 262 949-957.

Heshmat H 1993 Wear reduction systems for coal-fueled diesel engines - Experimental results and hydrodynamic model of powder lubrication Wear 162-164 518-528.

Hichri Y, Cerezo V and Do MT 2017a Friction on road surfaces contaminated by fine particles: Some new experimental evidences Proc IMechE Part J: J Engineering Tribology 231 1209-1225.

Hichri, Y. Cerezo, V. and Do, M.-T. 2017b Effect of dry deposited particles on the tire/road friction, Wear 376-377 1437-1444.

Hichri Y, Cerezo V, Do MT and Zahouani H 2017c Lubrication of the tire/road interface by fine particles: Tribological approach Proc. 23ème Congrès Français de Mécanique, 28 août - 1er septembre 2017, Lille, France (FR), AFM.

Mills R, Dwyer-Joyce R S, Loo-Morrey M 2009 The mechanisms of pedestrian slip on flooring contaminated with solid particles Tribology International 42 403-412.

Persson B N J, Tartaglino U, Albohr O and Tosatti E 2005 Rubber friction on wet and dry road surfaces: the sealing effect Physical Review B71 DOI: 10.1103/PhysRevB.71.035428.

Shakely R B, Henry J J and Heinsohn RJ 1980 Effects of pavement contaminants on skid resistance Transportation Research Record 788, 23-28.

Vaze J and Chiew F H S 2002 Experimental study of pollutant accumulation on an urban road surface Urban Water 4 379-389.

Wilson D J 2006 An analysis of the seasonal and short-term variation of road pavement skid resistance PhD Thesis University of Auckland NZ. 